\title{
СТАТИСТИЧЕСКИЙ ВЕЙВЛЕТ-АНАЛИЗ
}

П.М. Мазуркин, д-р техн. наук, проф., акад. РАЕ и РАЕН, член Европейской Академии естествознания, kaf_po@mail.ru,

Поволжский государственный технологический университет, Йошкар-Ола

Аннотация. Приведены примеры моделирования, идентификацией суммы асимметричных вейвлет-сигналов, поведения природных объектов: импульса электрокардиограммы здорового человека; естественной сушки проб луговой травы; взаимного влияния лесистости и распаханности территории; кризисной динамики и дефолта рубля 1998 г.; объема патентования и прогноз инноваций в России до 2020 г.; динамики лесных пожаров в национальном парке за 1982-2011 гг.; часовых приращений импульсов альфа-распада образца ${ }^{239} \mathrm{Pu}$ при максимуме солнечного затмения; амплитуды гравитационных волн от периода обращения 10 пульсаров в модели плещущейся Вселенной.

Ключевые слова: вейвлет-сигнал, обобщенная модель, идентификация, примеры, закономерности

\section{STATISTICAL WAVELET ANALYSIS P.M. Mazurkin}

Doctor of Engineering Science, Academician of RANS, member of EANS, Volga State University of Technology, Yoshkar-Ola, Russia, kaf_po@ mail.ru

Abstract. Examples of modeling, identification of the amount of asymmetric wavelet signal behavior of natural objects: the pulse of the electrocardiogram of a healthy person; natural drying samples meadow grass; mutual influence of forest cover and tilled territory; Crisis dynamics of the ruble and default 1998 .; volume of patenting and forecast innovations in Russia until 2020 y.; dynamics of forest fires in the national park for the 1982-2011 y.; hour increments pulses alpha decay ${ }^{239} \mathrm{Pu}$ sample at the maximum of the solar eclipse; amplitude of gravitational waves from the orbital period of 10 pulsars in the model splashing Universe.

Keywords: wavelet signal generalized model, identification, examples, patterns

Введение. В отличие от дедуктивного подхода к вейвлетному анализу $[1,2,17]$, исходящему из уравнений классической математики, предложен индуктивный подход, когда статистическая выборка первична и относительно неё идентифицируется структура и значения параметров обобщенной волновой функции $[9,10,11,15]$.

Любое явление (срез времени) или процесс (изменение во времени) по добротным табличным статистическим количественным данным (числовому полю) индуктивно можно идентифицировать суммой асимметричных вейвлет-сигналов вида

$$
\begin{array}{r}
y=\sum_{i=1}^{m} y_{i}, y_{i}=A_{i} \cos \left(\pi x / p_{i}-a_{8 i}\right), \\
A_{i}=a_{1 i} x^{a_{2 i}} \exp \left(-a_{3 i} x^{a_{4 i}}\right), p_{i}=a_{5 i}+a_{6 i} x^{a_{7 i}},
\end{array}
$$

где $y$ - показатель (зависимая переменная), $i$ - номер составляющей статистической модели (1), $m$ - количество членов модели, зависящее от достижения остатков от (1) погрешности измерений, $x$ - объясняющая переменная, $A_{i}$ - амплитуда (половина) колебания (ордината), $p_{i}$ - полупериод колебания (абсцисса), $a_{1} \ldots a_{8}$ - параметры модели (1), определяемые в программной среде CurveExpert (URL: http://www.curveexpert.net/).

По формуле (1) с двумя фундаментальными физическими постоянными $e$ (число Непера или число времени) и $\pi$ (число Архимеда или число пространства) образуется изнутри изучаемого явления и/или процесса квантованный вейвлет-сигнал.

Далее покажем несколько разных примеров вейвлет-анализа. 
Асимметричные сигналы электрокардиограммы. Цель - получение математической модели ЭКГ сигнала [13]. Задан один период электрокардиографического сигнала без патологии в системе отсчета $U(t)$, где: $t$ - время, измеренное в миллисекундах (мc); $U$ - напряжение сердца в милливольтах (мВ). Сигнал дан на рисунке 1.

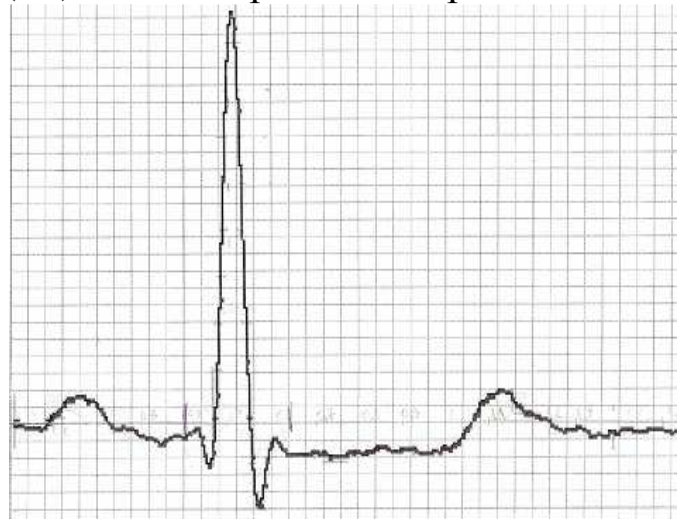

Рис. 1. Сетка для измерений сигнала сердца

Табличную модель обычно представляют в двух видах - в программе Excel или текстовом редакторе Word через координатные точки в принятой системе отсчета.

По мере усложнения формулы из предыдущего сеанса поиска принимаются все более точные записи коэффициентов (параметров модели). Завершается процесс сложным нелинейным многочленным уравнением. Полученное уравнение будет являться математической моделью данного одного ЭКГ сигнала.

График $U(t)$ двухчленной модели, соответ-

ствующий комплексу QRS сердца здорового человека, приведен на рисунке 2.

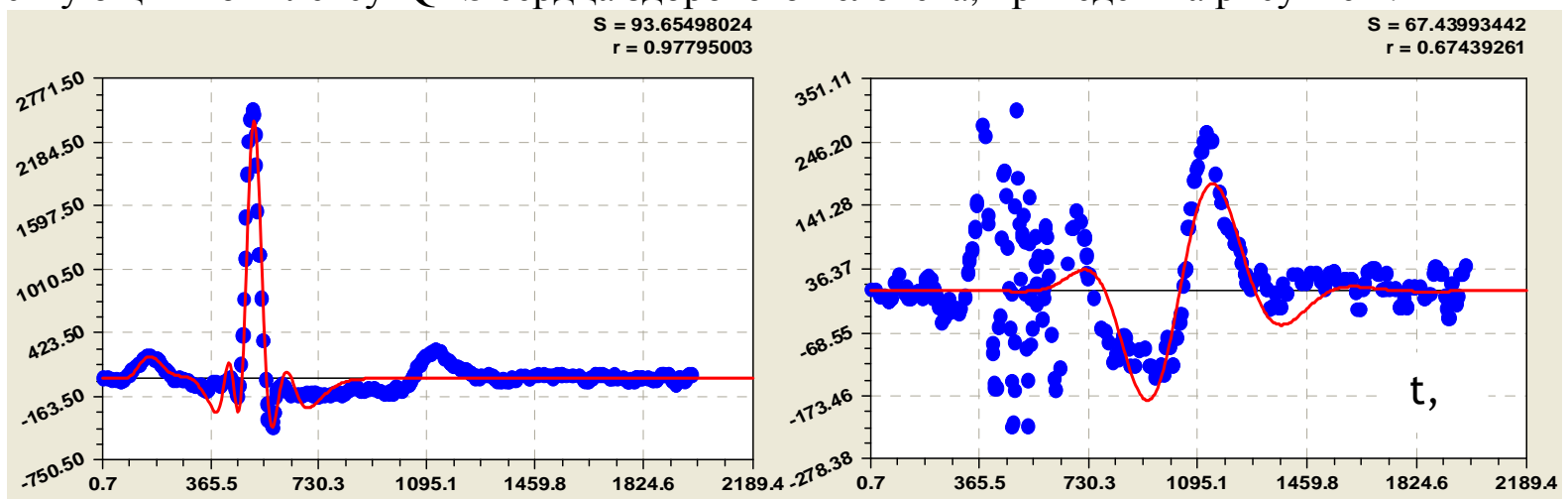

Рис. 2. Работа предсердия и желудочка сердца Рис. 3. Работа предсердия после желудочка сердца

По остаткам от модели на рисунке 2, соответствующей зубцу $\mathrm{T}$ сигнала электрокардиограммы сердца здорового человека, показан на рисунке 3. C пятой составляющей по тридцать третью получены новые асимметричные сигналы, но их принадлежность колебаниям сердечных мышц неявная. По-видимому, графики напряжения электрических сигналов могут принадлежать и другим органам человека.

Параметры модели (1) и коэффициент корреляции приведены в таблице 1.

Параметры математической модели ЭКГ сердца без патологии

\begin{tabular}{|c|c|c|c|c|c|c|c|c|c|}
\hline \multirow{2}{*}{$i$} & \multicolumn{4}{|c|}{ Амплитуда колебания, мВ } & \multicolumn{3}{c|}{ Полупериод и сдвиг колебания, мс } & \multirow{2}{*}{ Коэфф. } \\
\cline { 2 - 11 } & $a_{1 i}$ & $a_{2 i}$ & $a_{3 i}$ & $a_{4 i}$ & $a_{5 i}$ & $a_{6 i}$ & $a_{7 i}$ & $a_{8 i}$ & \\
\cline { 2 - 11 } & $2.59574 \mathrm{e}-028$ & 16.74766 & 0.078955 & 1.04811 & 0 & 0 & 0 & 0 & \multirow{2}{*}{0.9780} \\
\hline 2 & $1.42992 \mathrm{e}-149$ & 63.76683 & 0.013904 & 1.30529 & 10.59449 & 0.0022405 & 1.34410 & 3.18773 & \\
\hline 3 & $-3.40070 \mathrm{e}-033$ & 14.31631 & 0.000120 & 1.77400 & 21.15976 & 0.21683 & 0.87313 & 0.52152 & \\
\hline 4 & $-1.67937 \mathrm{e}-064$ & 25.57819 & 0.021603 & 1.01816 & 244.7042 & 0.0030608 & 0.98941 & 5.23804 & 0.6740 \\
\hline
\end{tabular}

Первые три составляющие дают коэффициент корреляции 0,9780. Поэтому уравнение (1) вполне достаточное для того, чтобы облегчить кардиологу диагностику сердца по цифровой электрокардиограмме.

Сигнал ЭКГ измеряется через 0,001 с до 2200 мс.. Обработка сигналов в сейсморазведке требует шкалу времени также через 0,001 с до 2500 мс [1, с.29, рис. 1.1]. В нейродинамике применяется шкала времени через 1 с до 1000 с [2, с.90, рис. 2.2а]. В разных примерах измерений и вейвлет-анализа применяются другие единицы времени.

Динамика массы влаги в ходе естественной сушки проб травы. В процессе естественной сушки срезанной надземной части травы происходят, по крайней мере, два 
процесса: во-первых, обезвоживание еще не мертвых клеточных структур от действия тепла воздуха; во-вторых, удержание влаги омертвляющимися клетками до испарения свободной влаги. В этом примере единицей времени является 1 час до 2000 ч [16].

Динамика массы пробы № 1 в ходе естественной сушки срезанной пробы травы до готового сена на пробной площадке характеризуется уравнением (1) в виде

$$
\begin{gathered}
m_{t}=m_{t 1}+m_{t 2}+m_{t 3}+m_{t 4}, \\
m_{t 1}=248,199, m_{t 2}=656,388 \exp \left(-0,027137 t^{0,97918}\right), \\
m_{t 3}=A_{1} \cos \left(\pi t / p_{1}-0,23480\right), A_{1}=-26,05914 \exp (-0,0036376 t), \\
p_{1}=6,93112+0,00019461 t, m_{t 4}=A_{2} \cos \left(\pi t / p_{2}+2,38942\right), \\
A_{2}=7,05798 t^{0,55718} \exp (-0,029730 t), p_{1}=19,31141+0,032157 t .
\end{gathered}
$$

В формуле (2) имеются следующие условные обозначения: $m_{t}$ - масса пробы тра-

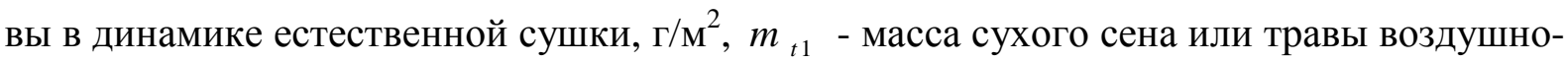

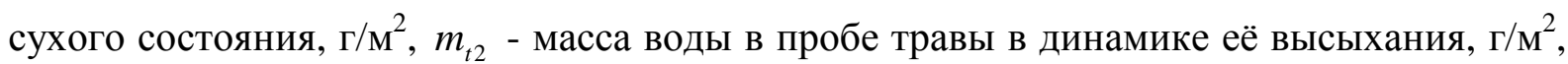

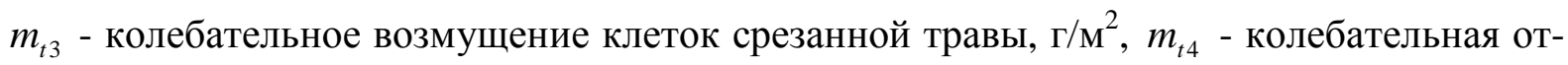
дача свободной воды клетками травы, $г / \mathrm{M}^{2}, t$ - время естественной сушки с момента срезания пробы травы, ч, $m_{t 60}=656,388$ - масса исходной влаги в травяной пробе, $г \mathrm{M}^{2}$, $A_{1}$ - амплитуда (половина) возмущения клеток пробы травы, г/м², $A_{2}$ - амплитуда (половина) возмущения клеток, пытающихся реанимировать круговорот влаги и получать минеральные вещества, г/м², $p_{1}$ - период (половина) возмущения на потерю влаги, ч, $p_{2}$ - период (половина) возмущения на спад обмена веществ, ч.

На рисунке 4 приведены графики, построенные по формуле (2), причем она имеет четкую физическую интерпретацию поведения травы после её срезки.

Максимальная относительная погрешность равна $\left|\Delta_{\max }\right|=1,46 \%$. Увеличенные волны показаны на рисунке 5 .

В течение первых 500 ч естественной сушки в пробе травы происходит резкое колебание динамичной массы $m_{t 4}$. Из графиков видно, что динамичная составляющая $m_{t 4}$ быстро угасает в пределах до 200 часов сушки, а менее динамичная составляющая $m_{t 3}$ продолжается.

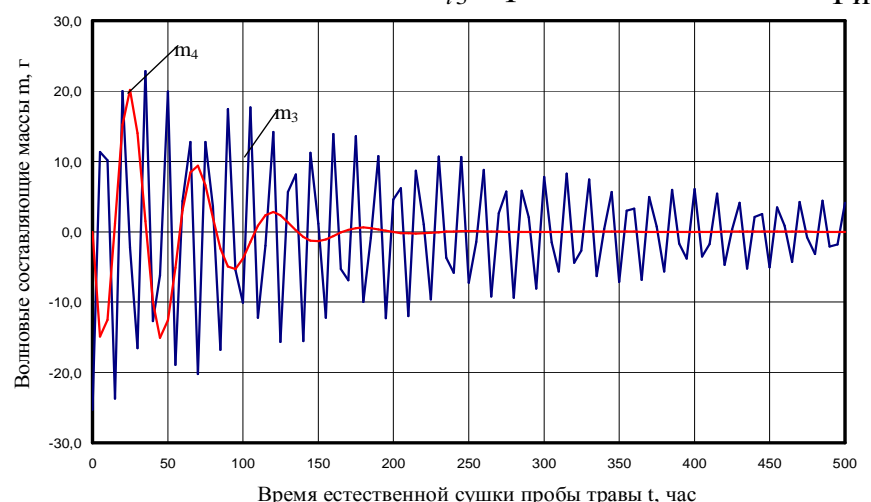

Рис. 5. Волновые составляющие (2) до 500 ч

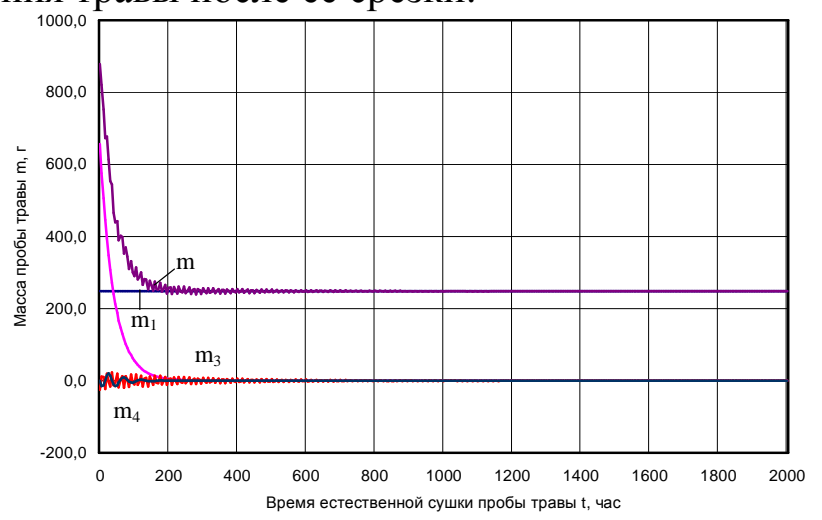

Рис. 4. Динамика массы травы на площадке № 1

Из четырех составляющих по всем 18 моделям типа (2) получены критерии для эколого-ландшафтной оценки луга: 1) рациональное время $t_{p}$ естественной сушки срезанной травы до готового сена, ч; 2) оптимальное время $t_{\text {opt }}$ сушки, ч; 3) максимальное время $t_{\text {max }}$ сушки травы, ч; 4) воздушно-сухая масса пробы травы $m_{1}=m_{c}$ или сена, г/м²; 5) мини-

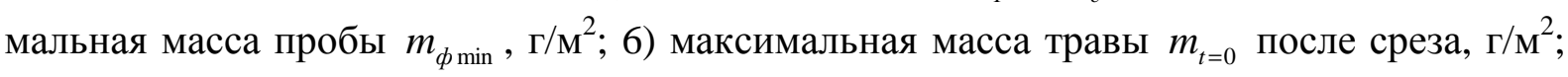
7) фактическая масса $m_{\phi 0}$ пробы срезанной травы, г/м²; 8) коэффициент динамичности массы $k_{c}$ высохшей травы от влажности воздуха, как отношение третьего члена (2) к 
первой; 9) коэффициент динамичности $k_{\text {вл }}$ колебательной отдачи влаги клетками травы при сушке; 10) общий коэффициент динамичности $k$ как отношение третьего с четвер-

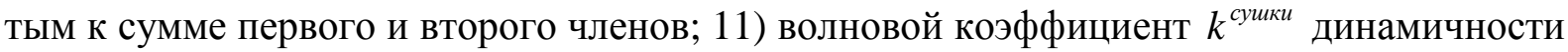
высыхания и увлажнения (сумма третьей и четвертой составляющих к первой); 12)

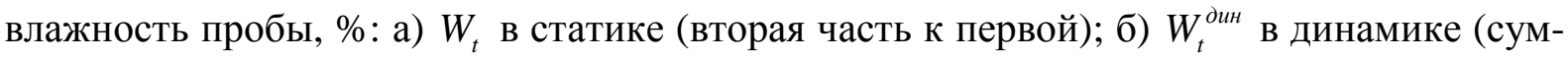
ма второй, третьей и четвертой частей к первой.

Далее покажем анализ земельного кадастра Кировской области в срезе времени (год) по взаимному влиянию леса (ядро биосферы) и пашни (ядро сельского хозяйства).

Влияние распаханности на лесистость территории. Модель влияния распаханности $\varsigma$ на лесистость $\xi$ была выполнена в программной среде CurveExpert-1.3 [14].

По всем 39 точкам (рис. 6а) получен тренд как закон экспоненциальной гибели

$$
\xi=89,423 \exp \left(-0,020159 \varsigma^{1,03112}\right) \text {. }
$$

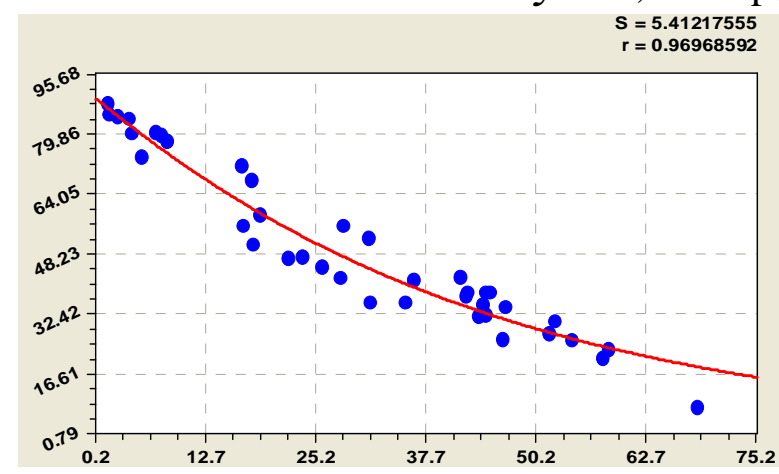

a) тренд закономерности

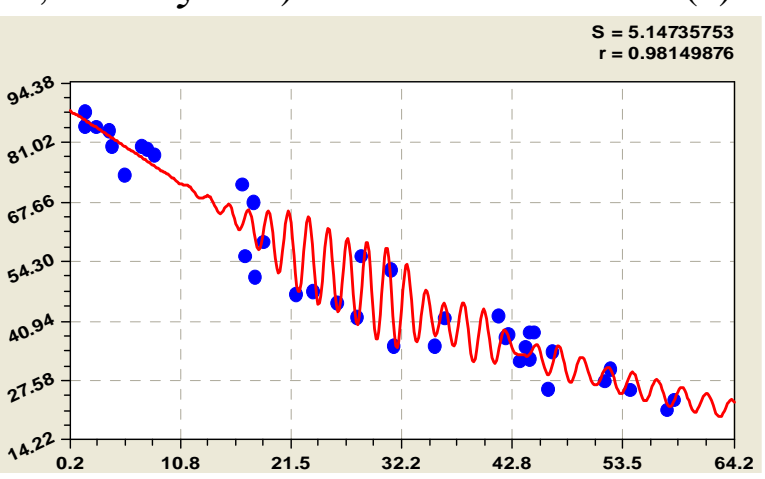

б) тренд и учет двух волн тремора

Рис. 6. Изменение лесистости от распаханности территории сельских районов Кировской области

После идентификации (1) была получена (рис. 6б) зависимость с двумя волнами: $\xi=88,1519 \exp \left(-0,015018 \varsigma^{1,09609}\right)-A_{1} \cos \left(\pi \varsigma / p_{1}+3,73625\right)-A_{2} \cos \left(\pi \varsigma / p_{2}-2,93701\right)$, (4)

$A_{1}=1,6271 \cdot 10^{-11} \varsigma^{11,66004} \exp \left(-0,37494 \varsigma^{1,03215}\right), p_{1}=0,98432-0,00022766 \varsigma^{1,29696}$,

$A_{2}=1,9405 \cdot 10^{-6} \varsigma^{4,86423} \exp \left(-0,073799 \varsigma^{1,06910}\right), p_{2}=1,17786+2,5262 \cdot 10^{-5} \varsigma^{1,36585}$.

Оба колебания имеют отрицательный знак, поэтому возмущения кризисные. На рисунке 6б видны три кластера муниципалитетов, имеющие разный стиль поведения.

Влияние лесистости на распаханность территории. А как же лесистость территории влияет на процент распаханности? [14].

Тренд получил (рис. 7а) формулу

$$
\varsigma=71,0128 \exp \left(-0,00074784 \xi^{1,84148}\right) \text {. }
$$

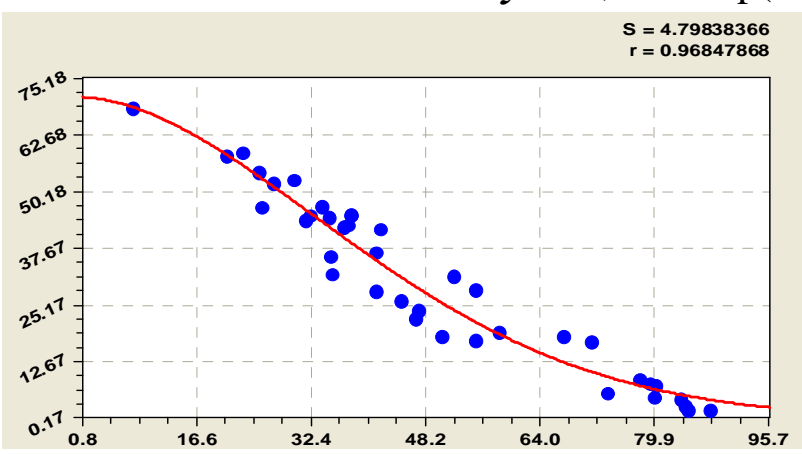

a) тренд закономерности

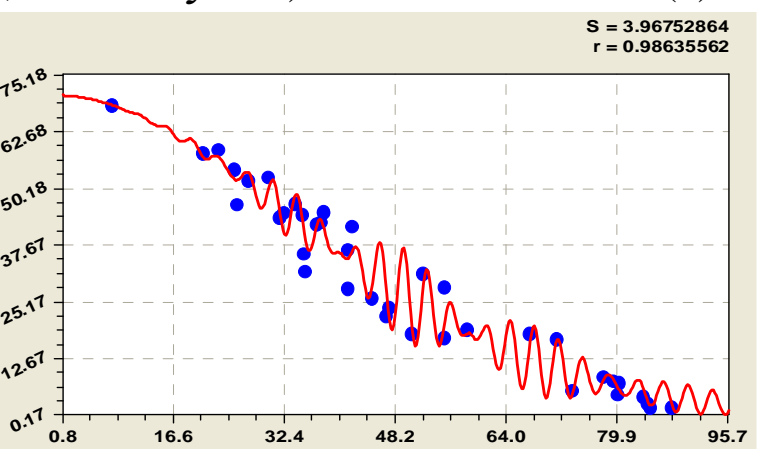

б) тренд и учет двух волн тремора

Рис. 7. Изменение распаханности от лесистости территории сельских районов Кировской области

Связность $\varsigma=f(\xi)$ лучше по сравнению со структурой $\xi=f(\varsigma)$. Таким образом, в основе взаимоотношений с землей все же сохранилась древняя традиция палевого земледелия, которая ныне в самом разгаре роста и развития находится на территории реки Амазонки. В Кировской области данную технологию к лесу не применяют. 
После идентификации тренда и двух вейвлетов кризисного колебательного возмущения сельских районов Кировской области была получена (рис. 7б) формула вида $\varsigma=70,6987 \exp \left(-0,00069398 \xi^{1,85728}\right)-A_{1} \cos \left(\pi \varsigma / p_{1}+1,92141\right)-A_{2} \cos \left(\pi \varsigma / p_{2}-3,46367\right),(6)$

$$
\begin{aligned}
& A_{1}=5,5756 \cdot 10^{-10} \xi^{7,15573} \exp \left(-0,025332 \xi^{1,35448}\right), p_{1}=1,48498+0,0024279 \xi^{0,70307}, \\
& A_{2}=1,8184 \cdot 10^{-5} \xi^{4,22294} \exp \left(-0,077257 \xi^{1,00723}\right), p_{2}=1,91267-0,00029107 \xi^{1,12624} .
\end{aligned}
$$

Всего было найдено еще шесть вейвлет-функций, из которых четыре являются адаптационными возмущениями (положительный знак впереди составляющей), а две кризисными колебаниями. Таким образом, общее количество кризисных возмущений также равно четырем. Всего в статистической модели образуется девять членов.

Первая адаптация происходила (рис. 8а) по формуле

$$
\begin{gathered}
\varsigma_{4}=A_{3} \cos \left(\pi \xi / p_{3}-2,35408\right), \\
A_{3}=0,0010605 \xi^{3,43357} \exp \left(-0,10955 \xi^{1,01955}\right), p_{3}=1,67066+0,0092795 \xi^{1,00397} .
\end{gathered}
$$
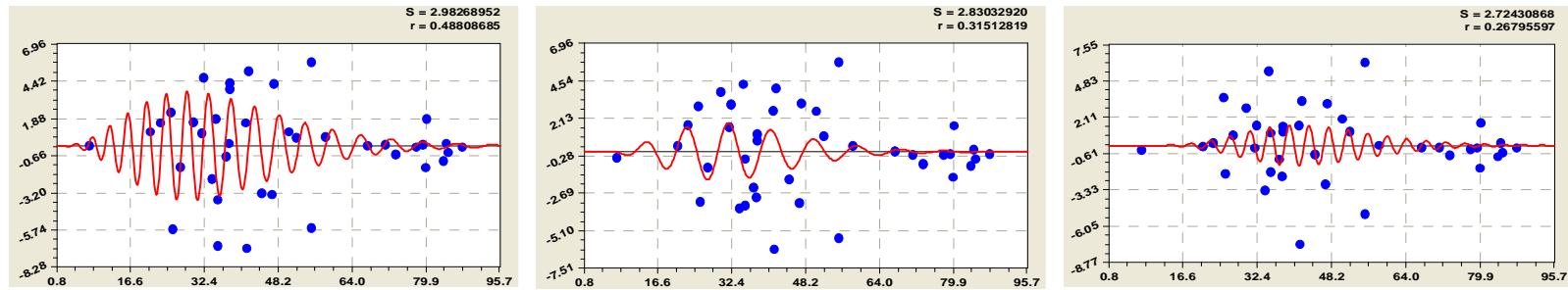

а) первая адаптация распаханности

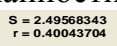
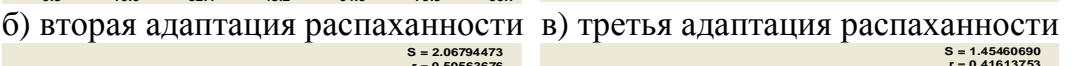

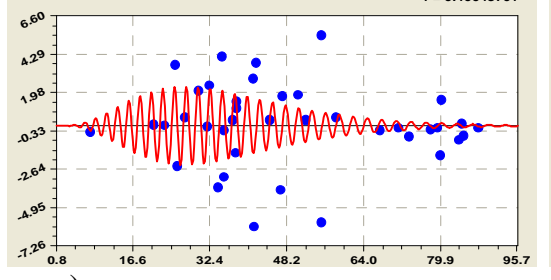

г) четвертая волна адаптации

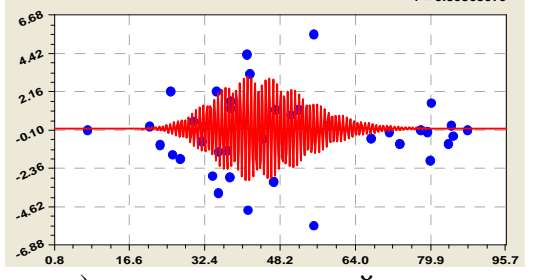

д) кризис по седьмой волне

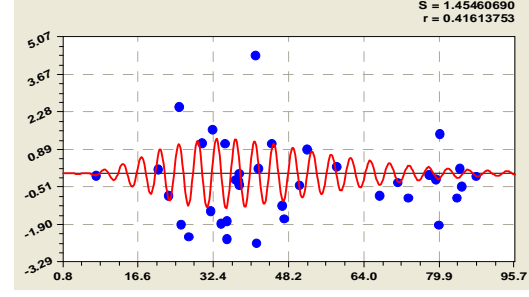

е) кризис по восьмой волне

Рис. 7. Дополнительные к модели (6) адаптационные и кризисные волны

Вторая адаптация (рис. 7б) произошла по зависимости

$$
\begin{gathered}
\varsigma_{5}=A_{4} \cos \left(\pi \xi / p_{4}+2,11013\right), \\
A_{4}=3,3093 \cdot 10^{-5} \xi^{4,28026} \exp \left(-0,06349 \xi^{1,18919}\right), p_{4}=1,29604+2,39925 \xi^{0,066338} .
\end{gathered}
$$

Приспособление волн идет слева направо, снижая значения остатков показателя распаханности территории. При этом заметно, что сельские районы с высоким уровнем лесистости не реагируют на показатель распаханности, так как на их территориях развита лесная промышленность.

Третья адаптация (рис. 7в) происходила по выражению

$\varsigma_{6}=A_{5} \cos \left(\pi \xi / p_{5}-1,71299\right)$,

$A_{5}=1,0430 \cdot 10^{-10} \xi^{8,30052} \exp \left(-0,11773 \xi^{1,11605}\right), p_{5}=2,13681-0,0017717 \xi^{0,72567}$.

Четвертая адаптация проходила (рис. 7г) по уравнению волны

$\varsigma_{7}=A_{6} \cos \left(\pi \xi / p_{6}-0,054939\right)$,

$A_{6}=0,00031957 \xi^{4,32976} \exp \left(-0,38203 \xi^{0,80143}\right), p_{6}=1,08772+0,0010660 \xi^{1,19734}$.

Третья кризисная волна с учетом первых, ранее найденных двух волновых составляющих уравнения (6) на рисунке 7д показано уравнение кризиса

$\varsigma_{8}=-A_{7} \cos \left(\pi \xi / p_{7}-6,14360\right)$,

$A_{7}=1,9079 \cdot 10^{-22} \xi^{17,9898} \exp \left(-0,27366 \xi^{1,09016}\right), p_{7}=0,38620$.

Восьмая составляющая получает постоянную частоту колебания.

Оказалось, что Верхошижемский и Слободской сельские районы имеют равную лесистость 55,4\%. Однако у них, соответственно, распаханность территории равна 28,4 и $17,1 \%$. Эту разницу в $28,4-17,1=11,3 \%$ и показывает программа CurveExpert-1.38. 
Четвертая кризисная волна получилась после исключения этих двух сельских районов (рис. 7е) в виде модели кризисного возмущения вида

$$
\begin{aligned}
& \varsigma_{9}=-A_{8} \cos \left(\pi \xi / p_{8}+0,33343\right), \\
& A_{8}=5,0120 \cdot 10^{-5} \xi^{4,16535} \exp \left(-0,17636 \xi^{0,92042}\right), p_{8}=1,89268+0,0079272 \xi^{0,58743} .
\end{aligned}
$$

По характеру расположения остатков было видно, что возможны и последующие волновые составляющие модели. Однако максимальная относительная погрешность уже приблизилась к погрешности измерений площади территории. Поэтому нет необходимости в дальнейшем наращивании конструкции общей статистической закономерности. Ясно, что в Кировской области параметр лесистости всё еще влияет на изменение коэффициента распаханности территории.

Кризисная динамика курса рубля. Фрагмент табличной модели для идентифкации функции типа $K=f(t)$ дан в таблице 2 (по суткам с 06.01.1993 по 31.12.2004 всего 2522 наблюдения) [7]. Для 06.01.1993 значение объясняющей переменной $t=0$.

Таблица 2

Табличная модель динамики курса рубля к доллару c 06.01.1993 по 31.12.2004 г.

\begin{tabular}{|c|c|c|}
\hline Дата & $t$, сутки & $K$, руб./\$ \\
\hline 22.01 .1993 & 22 & 493.0000 \\
\hline 20.01 .1993 & 20 & 474.5000 \\
\hline 15.01 .1993 & 15 & 442.0000 \\
\hline 13.01 .1993 & 13 & 423.0000 \\
\hline 06.01 .1993 & 6 & 417.0000 \\
\hline$\ldots$ & $\ldots$ & $\ldots$ \\
\hline 12.01 .2004 & 4070 & 28.9918 \\
\hline 09.01 .2004 & 4067 & 29.1350 \\
\hline 08.01 .2004 & 4066 & 29.2450 \\
\hline 06.01 .2004 & 4064 & 29.4545 \\
\hline 05.01 .2004 & 4063 & 29.4545 \\
\hline
\end{tabular}

Основная модель кризиса рубля получена по вычислительным возможностям программной среды CurveExpert-1.40 (рис. 8) в виде формулы

$$
K=K_{1}+K_{2}+K_{3}+K_{4}+K_{5},
$$

$K_{1}=1596,1347 \exp (-0,0028496 t)$,

$K_{2}=1.26648 \cdot 10^{-16} t^{7,47867} \exp \left(-0,0031169 t^{1,10028}\right)$,

$K_{3}=A_{1} \cos \left(\pi t / p_{1}-2,55294\right)$,

$A_{1}=-5,52024 \cdot 10^{-23} t^{9,43835} \exp \left(-0,0036385 t^{1,07839}\right)$,

$p_{1}=288,21469+758,00773 t^{0,020296} \exp \left(-0,00020804 t^{1,08303}\right)$,

$K_{4}=A_{2} \cos \left(\pi t / p_{2}+3,09398\right)$,

$A_{2}=-1,50797 \cdot 10^{6}(t-1826,3984)^{-1} \exp \left(-0,00031963 t^{1,23941}\right)$, $p_{2}=371,72980, K_{5}=A_{3} \cos \left(\pi t / p_{3}+0,20634\right)$,

$$
A_{3}=23035,3488(t-1825,8462)^{-1}, p_{3}=22,28533 .
$$

Каждая составляющая (3) имеет физический (экономический) смысл.

Первая составляющая по закону экспоненциальной гибели (закон Парето в экономике, Ципфа в биологии, Мандельброта в физике и Лапласа в математике) показывает естественное стремление российской экономической системы к снижению к 06.01.1993 набранного курса отечественной валюты $K_{0}=417$ руб./\$.

Вторая составляющая по биотехни-

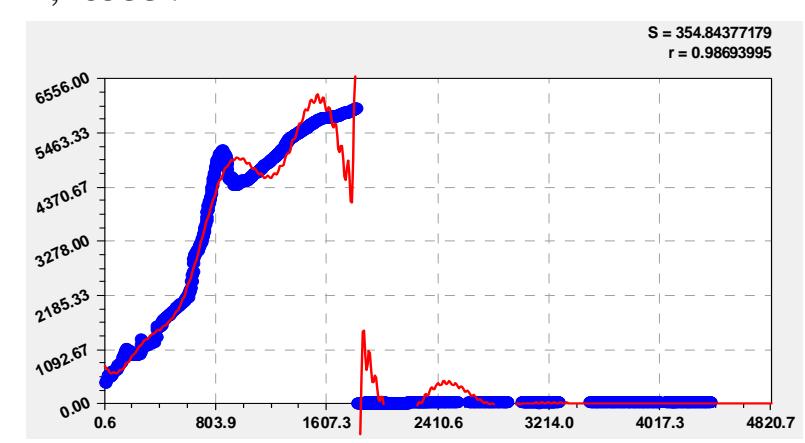

Рис. 8. График статистической модели (13) динамики курса рубля в кризисный период ческому закону показывает стрессовое возбуждение российской финансовой системы.

Вместе две составляющие дают тренд в виде не волновой (детерминированной) двухчленной формулы (рис. 8).

Остальные три члена являются волновыми функциями, которые определяют в каком-то смысле вычислительные подходы квантовой информатики. Но, несмотря на разрыв фактического курса рубля из-за деноминации в 1000 раз, нами было доказано, что удается дефолт описать гладкими функциями. Тем самым еще раз подтверждается, что социально-экономический кризис любой мощности можно описать статистическими моделями по добротным выборкам.

Третья составляющая в виде мегаколебания является основной, показывающей хаотическое и при этом явно несознаваемое управление экономикой. Это колебатель- 
ное возмущение чуть было не привело коллапсу и похоже на поведение явно расстроенных природных биологических систем.

Четвертая и пятая составляющие показывают дефолт рубля. Этот процесс дефолта нами описывается гиперболой типа

$$
y=k / x, k=-a \exp \left(-b t^{c}\right) \cos (\pi t / d+e), x=t-1826,3984,
$$

где $a, b, c, d, e$ - параметры модели (14), идентифицируемые в программной среде.

На рисунке 9 третья волна гиперболического колебания показана для точек, находящихся вблизи даты дефолта и она характеризуется формулой (14) с параметрами модели: $a=23035,3488$ руб./\$, $b=0, c=0, d=p_{3}=22,28533$ сутки, $e=1825,8462$ суток.

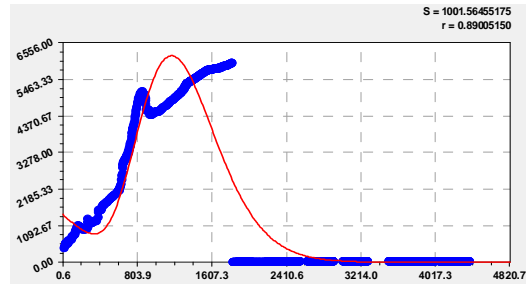

тренд из двух членов

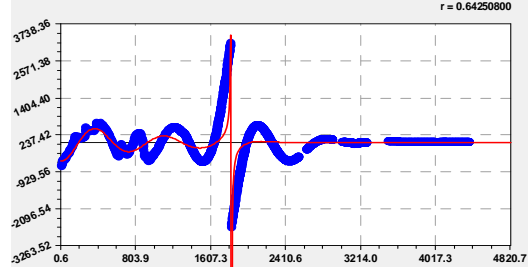

первая гипербола дефолта

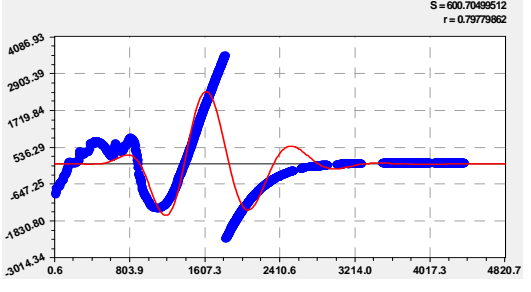

первое возмущение

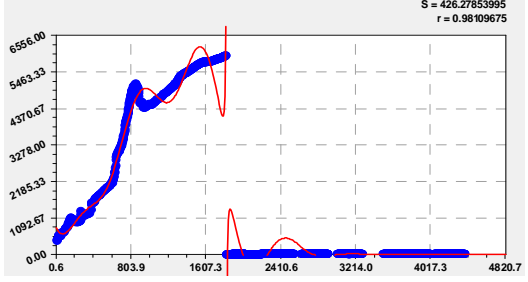

тренд и две волны

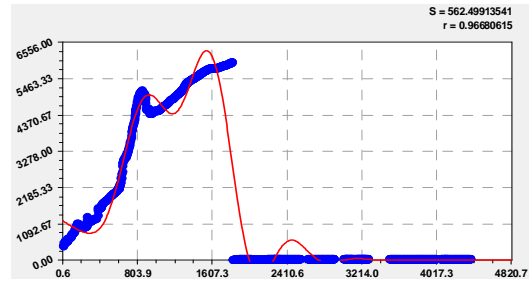

тренд и первая волна

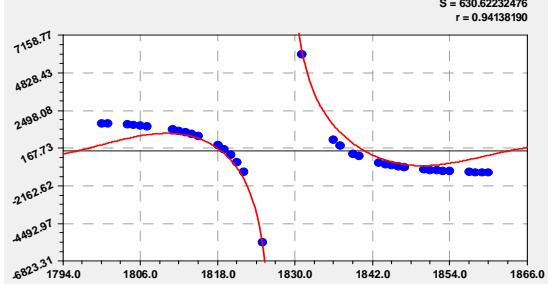

вторая гипербола дефолта

Рис. 9. Графики отдельных составляющих модели (13)

Из формулы (13) видно, что произошли два дефолта. Если бы не срочные меры финансовой стабилизации, то по стихии третьего члена курс рубля дошел бы вначале до уровня $1,5079710^{6}$ руб./\$, а затем еще до 23035, 35 руб./\$. На 06.01.1993 периоды равны: $2 p_{1}=2 \times 288,21462 \approx 576,4 ; 2 p_{2}=743,5 ; 2 p_{3}=44,6$ суток.

Объем патентования в России. Количество патентов на интеллектуальную собственность в нашей стране изменяется [12] по графикам на рисунке 10 по формуле

$$
\begin{gathered}
N_{R U}=N_{1}+N_{2}+N_{3}+N_{4}, \\
N_{1}=20137,366 \exp \left(0,0029067 t^{2,29800}\right), N_{2}=-3,70339 \cdot 10^{-5} t^{7,65749}, \\
N_{3}=A_{1} \cos \left(\pi t / p_{1}+0,80687\right), A_{1}=12501,360 \exp \left(-0,90186 t^{0,29987}\right), \\
p_{1}=7,24097-0,00026170 t^{3,06616}, N_{4}=A_{2} \cos \left(\pi t / p_{2}+3,66117\right), \\
A_{2}=7,22653 \cdot 10^{-68} t^{85,17581} \exp \left(-4,13391 t^{1,03752}\right), p_{2}=6,15466-0,20497 t^{0,96942} .
\end{gathered}
$$

Первая составляющая (15) является законом экспоненциального роста в полной форме. Он является естественной частью тренда. А вторая составляющая показывает кризисное (отрицательный знак перед членом) изменение численности российских патентов. В итоге двухчленный тренд на рисунке 1 получает тенденцию некоторого увеличения с 1998-го по 2007 годы. Но после 2007 г. вторая составляющая начинает резко превышать естественный первый член уравнения (15). Осознание сильнейшего кризиса в инновационном развитии страны по второму члену уравнения (15) позволило бы принять действенные меры и сбавить темпы спада объема патентования.

Оба колебания позитивные (положительный знак перед составляющими), амплитуда первого колебания имеет спад, а второго - характер стрессового возбуждения.

При этом первое волновое возмущение (рис. 10) резко учащается по частоте, что показывает потерю управляемости инновационными процессами. При полупериоде 7,24 года учащение дойдет до одного года в 2019 г. и далее станет отрицательным по значению (половина амплитуды станет равной всего 1108 шт.). Влиянием первого ко- 
лебания с 2020 г. можно пренебречь. Второе колебание закончится в 2015 г.

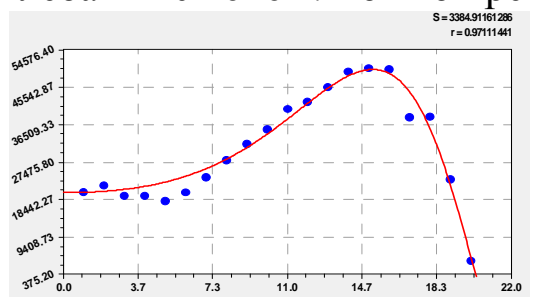

двухчленный тренд

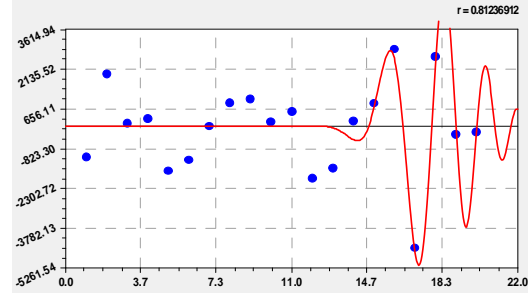

второе волновое возмущение

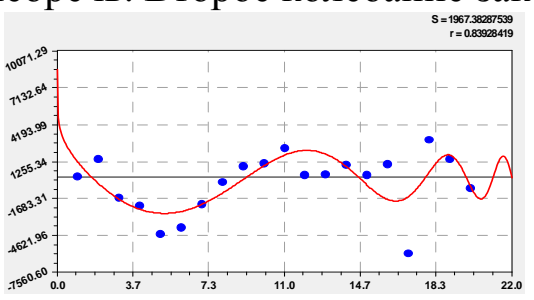

первое волновое возмущение

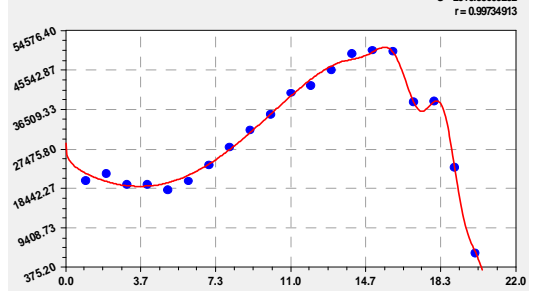

динамика патентов

Если не будет повышено генотипическое расстояние от прототипа к изобретению, то по прогнозу формулой (15) резко повысится объем патентования, но при этом патенты не будут повышать мировой технический уровень выпускаемой отечественной продукции. В итоге, как и прежде, более $70 \%$ патентов будут направлены на морально устаревшие технику и технологии. С 2017 г. объем патентования достигнет до кризисного 2007 г., но каждый патент будет иметь очень малые приращения по новизне, комплексности технического решенияов. Для коренной реформы промышленности и действительного перехода к инновационному пути развития страны и роста технологической базы экономики осталось всего 2017 - $2014=3$ года.

Динамический ряд лесных пожаров как череда сигналов. Как пример на рисунке 11 показаны графики физико-математического анализа динамики лесных пожаров за 1982-2011 гг. в «Марий Чодра» по нескольким вейвлетам (модели не даны).
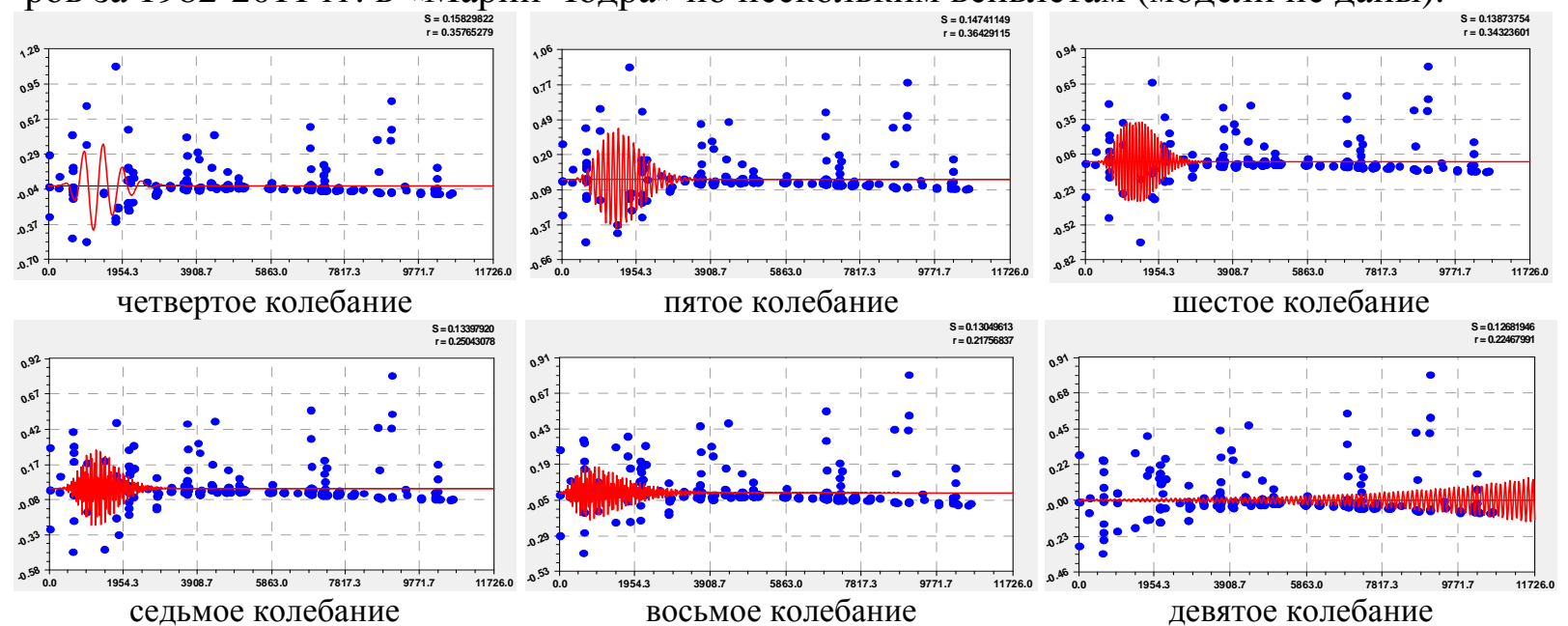

Рис. 11. Графики отдельных асимметричных вейвлет-сигналов из общей статистической модели динамики площади лесных пожаров от времени измерения в сутках за период 1982-2011 гг.

Причем по выявленным закономерностям можно было бы выполнить ориентировочный инерционный прогноз на горизонт прогноза, равный основанию прогноза (промежутку времени от нуля до последнего измерения лесного пожара), а также рабочий инерционный прогноз на одну треть периода прошлых измерений лесных пожаров. В итоге повышается оперативность тушения пожаров. Применение предложенного метода $[15,18,20]$ расширяет возможности территориального экологического мониторинга, повышает функциональные возможности системы типа «Лесной Дозор».

Альфа-распад при солнечном затмении. Влияние трех небесных тел СолнцаЗемли и луны на интенсивность часовых приращений альфа-активности образца ${ }^{239} \mathrm{Pu}$ показаны в статьях [3-6]. Например, после идентификации была получена (рис. 12) пятичленная (по пределу возможностей программной среды типа CurveExpert) формула

$$
I_{u}=I_{41}+I_{42}+I_{u 3}+I_{44}+I_{45},
$$




$$
\begin{aligned}
& I_{u 1}=11333,009, I_{42}=13,72924 t, I_{43}=A_{1} \cos \left(\pi t / p_{1}+0,85630\right), \\
& A_{1}=-1259,6144 \exp (-0,049053 t), p_{1}=13,83259-0,059446 t^{1,08961}, \\
& I_{44}=A_{2} \cos \left(\pi t / p_{2}+1,50517\right), A_{2}=4,28216 \cdot 10^{-39} t^{26,52258} \exp \left(-0,0063403 t^{1,67090}\right), \\
& p_{2}=2,18104, I_{45}=A_{3} \cos \left(\pi t / p_{3}-5,20128\right), A_{3}=-302,03608 t^{0,22076}, \\
& p_{3}=-7,67903+9,05505 t^{0,058383},
\end{aligned}
$$

где $t$ - время в часах, начиная от 04-05 часов 07 апреля 2005 года, $I_{\text {ч }}$ - часовые превышения числа импульсов, $I_{41}, I_{42}, I_{43}, I_{44}$ и $I_{45}$ - составляющие модели (16), $A_{1}, A_{2}$ и $A_{3}-$ амплитуды (половина) первого, второго и третьего колебательного возмущения гравитационной волны, $p_{1}, p_{2}$ и $p_{3}$ - полупериоды колебаний альфа-распада образца ${ }^{239} \mathrm{Pu}$.

В формуле (16) первая составляющая получила постоянное значение, а второй член имеет линейное изменение. Начальный период для трех колебаний соответственно равен $2 \times 13,83259 \approx 27,7$ ч, $2 \times 2,18104 \approx 5,1=$ const и $-2 \times 7,67903 \approx-15 ? 4$ ч.
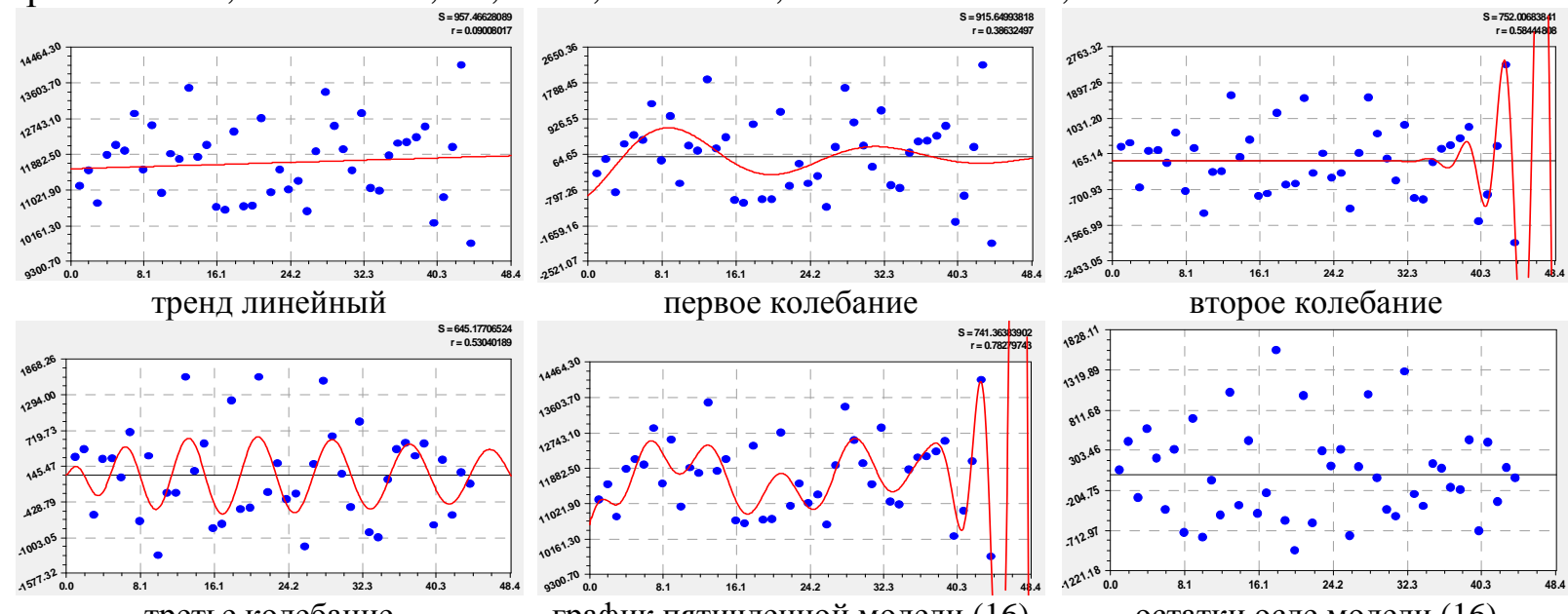

Рис. 12. Динамика часовых импульсов альфа-распада при максимуме солнечного затмения

Общая модель динамики часовых приращений импульсов включает 43 члена.

Фрактальный анализ вейвлетов. Количество импульсов радиоактивного распада всегда превышает $I_{0}=300 \mathrm{c}^{-1}$. Поэтому для фрактальной группировки введем уровни $U=I_{u}^{\text {ocm }} / I_{0}$ [3-6]. Нулевой уровень равен максимальному остатку $\left|\varepsilon_{\max }\right|=14034$ часовых приращений импульсов, деленному на 300 , т.е. $U_{0}=I_{u}^{\max } / I_{0}=14034 / 300=46,8$.

После идентификации была получена формула рангового снижения максимальных остатков $\left|\varepsilon_{\max }\right|$ в виде двухчленного уравнения

$$
\begin{array}{r}
\left|\varepsilon_{\max }\right|=16333,904 \exp (-2,08048 R)-A \cos (\pi R / p+1,29249), \\
A=8397,012 \exp (-0,33912 R), p=9,51595+0,059570 R^{1,75114} .
\end{array}
$$

Первый член является законом Мандельброта для фрактального разложения.

Остатки показывают, что в пределах рангов 0-11 возможно еще одно волновое возмущение параметров моделей вейвлетов. Далее модели располагаются спокойнее.

Фракталы максимума солнечного затмения. Модель включает три фрактальных уровня [5]. Первый уровень равен $U_{1}=7,4$. Тогда получается снижение с 46,8 до 7,4 в 6,3 раза. Второй уровень фрактальной группировки при $U_{2}=5,3$ соответствует трем волнам при рангах $R=3,4,5$. На рисунке 13 даны графики членов с рангами 6-11.

Все члены модели имеют коэффициент корреляции более 0,3 и поэтому каждая волновая закономерность значима. При этом 11-ая составляющая как бы замыкает группу, получая амплитуду по закону экспоненциальной гибели. Этот факт означает, что на этап максимума солнечной активности влияет предыдущий этап ламинарной фа- 
зы. Поэтому все вейвлеты взаимосвязаны на шкале времени бесконечными вейвлетами. А конечномерные вейвлеты показывают этап или часть общего процесса.

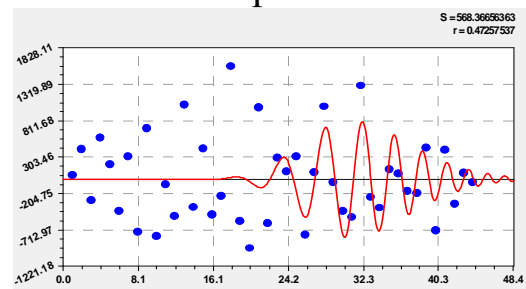

шестая составляющая

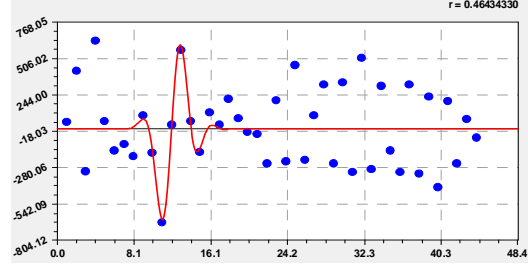

девятая составляющая

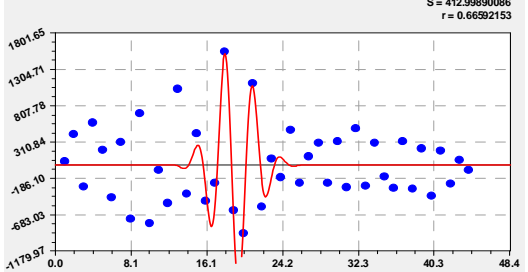

седьмая составляющая

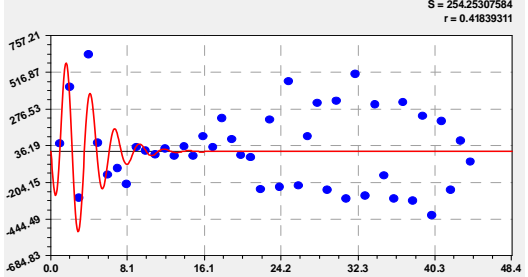

десятая составляющая

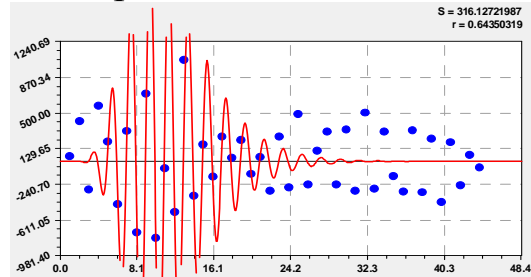

восьмая составляющая

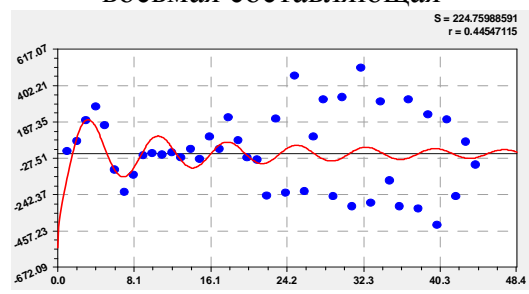

11-ая составляющая

Рис. 13. Динамика часовых импульсов альфа-распада при максимуме солнечного затмения

Последний вйевлет-сигнал получил коэффициент корреляции 0,8041 и это относит закономерность №43 в группу с сильными факторными связями. Таким образом, нами доказана возможность статистического моделирования возмущений гравитационных волн от действия максимума солнечного затмения.

Модель плещущейся Вселенной. Из графиков на рисунке 14 видно, что гравитационное колебательное возмущение звёздных систем по амплитуде $h$ происходит в интервале периода обращения $T$ пульсаров 0,1-1,0 сутки. В этом интервале находятся семь звёздных систем, кроме трех пульсаров PSR J0700+6418, PSR J1829+2456 и PSR J1439-5501. Они расположены справа от пойнтер-точки 1,0 [8, 19].

Интервал периода обращения пульсаров во втором колебании изменяется от 0,4 до 2,2-2,3 сутки. Два колебания есть в диапазоне в 0,4-1,0 сутки.

Из формулы видно, что периоды колебаний амплитуды гравитационных волн при условии $T=0 \quad$ равны у первого вейвлета $2 \times 0,024095462=$ 0,048190924 и второго колебания $2 \times 0,13093392=$ 0,26186784 (надо учесть еще множитель $10^{-22}$ ).

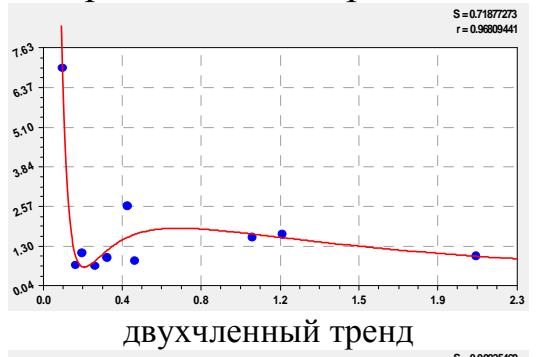

$S=0.00035460$
$r=0.99371626$

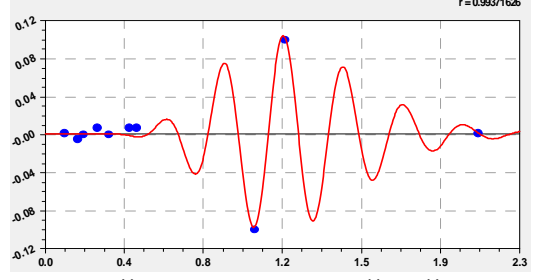

второй асимметричный вейвлет

Рис. 14. График статистической модели (18) изменения амплитуды гравитационных волн от периода обращения 10 пульсаров

Все четыре члена дают модель плещущейся Вселенной (рис. 14) вида

$$
\begin{gathered}
10^{22} h_{0}=h_{01}-h_{02}-h_{03}+h_{04}, \\
h_{01}=10045843,0 \exp \left(-13,119916 T^{0,12626636}\right), h_{02}=756195,75 \exp \left(-10,623253 T^{0,16669093}\right), \\
h_{03}=A_{1} \cos \left(\pi T / p_{1}-1,9456439\right), A_{1}=8808164,2 T^{6,9036732} \exp \left(-20,080126 T^{0,7992200}\right), \\
p_{1}=0,024095462+0,0073109174 T^{1,0864200}, h_{04}=A_{2} \cos \left(\pi T / p_{2}-3,2854931\right), \\
A_{2}=2631,0001 T^{9,3234819} \exp (-9,7213955 T), p_{2}=0,13093392+0,0014765024 T^{2,122200},
\end{gathered}
$$

Отношение второго колебания к первому будет равно 5,43398. Частота двух колебаний гравитационной волны при условии $T=0$ у бесконечно быстро вращающегося 
теоретически возможного пульсара будут равны 20,750805e22 и 3,818721e22.

К двум апериодическим колебаниям тренда, которые выразились модифицированными законами Лапласа, добавляются два асимметричных вейвлета.

Заключение. Доказана применимость статистической модели (1) к любым природным объектам, начиная от импульса сердца человека до модели плещущейся вселенной. Например, в гравитационных волнах между Солнцем, Землей и Луной в период максимума солнечного затмения происходят многоуровневые процессы, которые точно можно уловить по часовым приращениям импульсов альфа-распада от образца ${ }^{239} \mathrm{Pu}$.

И, наконец, есть группа закономерностей, по остаткам сравнимая с погрешностью измерений. Этот факт доказывает, что метод измерения возмущений гравитационных волн прибором с импульсами альфа-распада ${ }^{239} \mathrm{Pu}$ является очень точным, позволяющим провести регистрацию по отдельным импульсам.

\section{Литература}

1. Вейвлеты в геофизике: обработка сигналов в сейсморазведке / А.Е. Руннова, А.Е. Храмов, А.А. Короновский, А.Н. Павлов, А.В. Иванов. М.: Университетская книга, 2013. 190 с.

2. Вейвлеты в нейродинамике и нейрофизиологии / А.А. Короновский, В.А. Макаров, А.Н. Павлов, Е.Ю. Ситникова, А.Е. Храмов. М.: ФИЗМАТЛИТ, 2013. 272 с.

3. Мазуркин П.М. Вейвлет-анализ альфа-активности образца ${ }^{239} \mathrm{Pu}$ солнечного затмения // Наука и мир: международный научный журнал. 2013. № 1(1). С.94-104.

4. Мазуркин П.М. Вейвлет-анализ альфа-активности ${ }^{239} \mathrm{Pu}$ во времени солнечного затмения // Наука и мир: международный научный журнал. 2014. № 1(5). С.94-104.

5. Мазуркин П.М. Вейвлет-анализ часовых приращений альфа-активности ${ }^{239} \mathrm{Pu}$ при максимуме солнечного затмения // Наука и мир: международный научный журнал. 2014. № 2(6). Том 1. С.46-55.

6. Мазуркин П.М. Вейвлет-анализ часовых приращений альфа-активности ${ }^{239} \mathrm{Pu}$ после солнечного затмения // Наука и мир: международный научный журнал. 2014. № 3(7). Том 1. С.31-40.

7. Мазуркин П.М. Вейвлет-анализ кризисной динамики курса рубля // Междисциплинарные исследования в области математического моделирования и информатики. Матер. 3-й научно-прак. internetконф. Ульяновск: SIMJET, 2014. С 260-268.

8. Мазуркин П.М. Вейвлет-сигналы гравитационных волн от пульсаров // Исследования основных направлений технических и физико-математических наук: сб. научных тр. по матер. II Междунар. научн. конф. 10 мая 2014 г. Волгоград: Изд-во «Научное обозрение», 2014. С. 16-23.

9. Мазуркин П.М. Геоэкология: Закономерности современного естествознания. Йошкар-Ола: МарГТУ, 2006. 336 с.

10. Мазуркин П.М. Идентификация статистических устойчивых закономерностей // Наука и мир: международный научный журнал. 2013. № 3(3). С.28-33.

11. Мазуркин П.М. Решение 23-ой проблемы Гильберта Междисциплинарные исследования в области математического моделирования и информатики. Матер. 3-й научно-прак. internet-конф. Ульяновск: SIMJET, 2014. С 269-277.

12. Мазуркин П.М. Сравнительная динамика патентования в России и США // Интеллектуальная собственность. Промышленная собственность. 2014. №8. С.52-61.

13. Мазуркин П.М.. Васильев А.А. Асимметричные сигналы электрокардиограммы // Охрана и защита, обустройство, индикация и тестирование природной среды. Сб. статей, под ред. проф. П.М. Мазуркина. М.: Академия Естествознания, 2010. С. 344-348.

14. Мазуркин П.М., Михайлова С.И. Территориальное экологическое равновесие = Territprial ecological balance: аналит. обзор; Учреждение Рос. акад. наук Гос. публич. науч.-техн. б-ка Сиб. отд-ния РАН, Марийс. гос. техн. ун-т. Новосибирск : ГПНТБ СО РАН, 2010. 430 с. (Сер. Экология. Вып. 94).

15. Мазуркин П.М., Филонов А.С. Математическое моделирование. Идентификация однофакторных статистических закономерностей: учебное пособие. Йошкар-Ола: МарГТУ, 2006. 292 с.

16. Михайлова С.И., Мазуркин П.М. Ландшафтно-экологическая роль пойменного луга малых рек. Йошкар-Ола: МарГТУ, 2011. 154 с.

17. Фрактальный анализ в флювиальной геоморфологии / И.К. Андронике, А.В. Иванов, А.А. Короновский, М.А. Мельник, А.В. Поздняков, С.А. Чупикова, И.А. Яшков. Под ред. А.В. Иванова, А.В. Позднякова. М.: Университетская книга, 2013. 188 с.

18. Mazurkin P.M. Analisi dendrocronologica series. Italian Science Review. 2014; 5(14). PP. 163-169. Available at URL: http://www.ias-journal.org/archive/2014/may/Mazurkin.pdf

19. P.M. Mazurkin, "Asymmetric Wavelet Signal of Gravitational Waves." Applied Mathematics and Physics, vol. 2, no. 4 (2014): 128-134. doi: 10.12691/amp-2-4-2.

20. P.M. Mazurkin, "Wavelet Analysis of a Number of Prime Numbers." American Journal of Numerical Analysis, vol. 2, no. 2 (2014): 29-34. doi: 10.12691/ajna-2-2-1. 